\title{
INDUSTRY "MANUFACTURE OF FOOD PRODUCTS, BEVERAGES AND TOBACCO PRODUCTS” AS ECONOMIC UNIT IN THE BALTIC STATES AND FINLAND
}

\author{
Andrejs Jaunzems, Ilze Balode \\ Ventspils University of Applied Sciences, Latvia \\ jaunzems@venta.lv
}

\begin{abstract}
The research is devoted to the dynamic comparative analysis of the industry "Manufacture of food products, beverages and tobacco products" (C10-C12) as an economic unit in the Baltic States and Finland. The theoretical background of the current study in the broad sense is the classical Input-Output analysis offered by W. Leontief and A. Ghosh, which is explored, for example, in the book "Input-Output Analysis. Foundations and Extensions" by Ronald E. Miller and Peter D. Blair, and in scientific publications, as well. The empirical material of the study is the National Input-Output Tables for the Period 2000-2014 available at the World Input-Output Database with its unified structured statistical information in monetary terms. The original modification of the classical input-output model created by Jaunzems (2017) especially for the structure of National Input-Output Tables allows us to calculate and to interpret an array of economical and technological marginal indicators characterizing the industry $\mathrm{C} 10-\mathrm{C} 12$ : technological interindustry coefficients, Leontief inverse, monetary allocation coefficients, Ghosh inverse. The authors perform the analysis of the industry's C10-C12 gross output, final demand, value added, direct and total backward linkages, direct and total forward linkages. The main conclusions of the study apply the purchases' vector structure, the gross output sales structure, and the sources for value added formation as well. The analysis is provided in the dynamic and comparative aspect, comparing Estonia, Finland, Latvia, Lithuania. Founded conclusions about the industry C10-C12 different efficiency require more detailed socio-economic causality analysis.
\end{abstract}

Keywords: industry C10-C12, Input-Output, interindustry coefficients, Leontief inverse, allocation coefficients, Ghosh inverse.

\section{Introduction}

The research is devoted to the dynamic comparative analysis of the industry "Manufacture of food products, beverages and tobacco products" $(\mathrm{C} 10-\mathrm{C} 12)$ as an economic unit in the Baltic States and Finland. The general theoretical background of the current study in the wide sense is the classical InputOutput analysis offered by W. Leontief and A. Ghosh [1-3] and methods of linear algebra as well. Systematic introduction and implementation of the Input-Output model are carried out by Miller and Blair [4]. The Journal of the International Input-Output Association https://www.iioa.org/ "Economic Systems Research" offers to furnish information about broad spectrum of the Input-Output Economics applications [5].

Origins of Input-Output Economics are dating back to the Francois Quesnay, who presented in 1758 the Economic table (Tableau économique). The Economic table shows the flow of production or cash taking place between the three classes: landowners, agricultural labourers, artisans and merchants. The further contribution was made by Léon Walras's work "Elements of Pure Economics" on general equilibrium theory [6;7]. Wassily Leontief was the first to use a matrix representation of a national economy, to calculate and to interpret so called Leontief inverse matrix, and earned the Nobel Prize in Economics for his development of Input-Output Economics.

Nowadays many economists are speaking about broad fundamental crisis of capitalism. They discuss the purposefulness of global planning in order to control the Earth resources' sustainable spending. For that is urgent to remember the Gosplan's method of material balance planning in the USSR. It seems that the socio-economic role of Input-Output analysis has to be rethought. Indeed, in the time of global information triumph the role of Input-Output Economics must take more significant place in science, in the field of policy making to simulate and analyse complex trends in economies, in the management, and education. The broad holistic approach to the Input-Output Economics implementation has to be developed, very important part of which is unified optimally structured information around the world, or at least around the OECD countries (including National Accounts, Supply tables, Use tables, Symmetric Input-Output tables). The first signals about growing interest to the Input-Output Economics already appears. Let us mention just three very interesting and easily available books richly highlighting the newest tendencies in the Input-Output Economics [8-10]: 
- Jan Oosterhaven. Rethinking Input-Output Analysis: A Spatial Perspective. - University of Groningen, The Netherlands. Series: SpringerBriefs In Regional Science. Publisher: Springer Nature Switzerland AG. Year: 2019.

- Editor Kakali Mukhopadhyay. Applications of the Input-Output Framework. - McGill University, Montreal, QC, Canada. Publisher: Springer Nature Singapore Pte Ltd. Year 2018.

- Tan, R. R., Aviso, K. B., Promentilla, M.A.B., Yu, K. D. S., \& Santos, J. R. Input-output models for sustainable industrial systems: Implementation using LINGO. - Springer, Singapore. Year 2018.

All tables and all figures in the current paper are created by the authors by applying NIOT data, mathematical models and Microsoft Excel tools.

\section{Materials and Methods}

As it is mentioned in the introduction, the current research is devoted to the dynamic comparative analysis of the industry "Manufacture of food products, beverages and tobacco products" (C10-C12) as an economic unit in the Baltic States and Finland with help of Input-Output models. The industry "Manufacture of food products, beverages and tobacco products" consists of meat industry, dairy industry, beverages industry, grain processing, animal feed manufacture, other food industries, tobacco industry. We consider each industry of national economy as a separate economic unit, whose actions are the fusion of the internal firm owners' economic decisions and actions in the real time and under the real political, economical, social, technological, international, legal and bio-environmental (in abbreviator - PESTILB) factors. Thijs ten Raa [11] provides the following interpretation of industry: "All industries are machines transforming factor inputs into value added. In other words, industries have multiple (factor) inputs, but essentially a single "output", namely value added." We would like to take the liberty to correct assertion of Thijs ten Raa. In our opinion, in Input-Output Economics the industry is an economic agent, which in definite period of time creates the input vector to buy and with help of purchased input and owned current technologies creates the output vector to sell. Economic equilibrium requires equality between the value of input and the value of output. The main questions are: what is the economic unit's C10-C12 purchases structure and what is its gross sales structure, how the final demand of industry product and value added of industry are related, what are the sources for value added formation.

The empirical material of the study is the National Input-Output Tables (NIOT) (www.wiod.org) with its unified structure in monetary terms available in the World Input-Output Database (WIOD) November 2016 Release [12]. WIOD covers 28 EU countries and 15 other major countries in the world for the period from 2000 to 2014. According to NIOT the United Nations 3-letter codes are used: EST (Estonia), FIN (Finland), LVA (Latvia), LTU (Lithuania). Data for 56 sectors are classified according to the United Nations industry classification system "International Standard Industrial Classification of All Economic Activities (ISIC Rev. 4)".

The 2016 release was financially supported by the Dutch Science Foundation and European Commission Services. The economists in EU highly appreciate research possibilities provided by WIOD and are consent about emergency to expand the WIOD after 2014.

The mathematics of Input-Output economics, the calculation tools and ideas of application nowadays are sufficiently developed, however, there still are serious problems with the data collection and preparation. The data collection and preparation process for the input-output accounts is traditionally regarded as necessarily labour and computer intensive. For that reason, the Input-Output tables are often published a long time after the year in which the data were collected, typically as much as 5-7 years after. Besides that, not all countries collect the input-output data even though the standards for the data collection are defined by the United Nations through the System of National Accounts (SNA). Obviously, real situation in input-output data collection and preparation area disgraces the modern statistic institutes and modern information technologies.

Let us shortly expound the theoretical input-output framework, key concepts, and methods used with respect of the structure of given NIOT information. The main tool applied to identify the most important reasons, which cause the similarity and differences in the value added formation in the industry C10-C12 in EST, FIN, LVA, LTU in the sense of value added creation power, is the original 
version of the Input-Output model specifically constructed by the author [13] with regard to the given structured statistical information NIOT.

The structure of NIOT is conditionally shown in Table 0 . We hope that the sense of each row and each column is clear without additional detailed explanation. We have presented a number of papers, which examine in detail the theoretical methods used in input-output research, and in order to be reader friendly we have also illustrated the theoretical content with simple numerical examples. We kindly appeal to the readers to get acquainted with the chapter "Materials and methods" in the open access papers $[14,15,16]$, which can be easily accessed.

Let us stress that in the different institutes of statistics we can encounter Input-Output tables in many different forms. In our opinion, the NIOT is prepared in the almost optimal, handy and users' friendly form. We must be grateful to the NIOT elaborators.

Table 0

Structure of NIOT table compiled in current prices, expressed in millions of US dollars

\begin{tabular}{|c|c|c|c|c|c|c|c|c|c|}
\hline Code & Origin & Code1 & Code2 & Code3 & CONS_h & CONS_np & CONS_g GFCF & INVEN & \begin{tabular}{|l|l|} 
EXP & GO \\
\end{tabular} \\
\hline Code1 & Domestic & & & & & & & & \begin{tabular}{|l|l|} 
gol \\
\end{tabular} \\
\hline Code2 & Domestic & & & & & & & & go2 \\
\hline Code3 & Domestic & & & & & & & & go3 \\
\hline Code1 & Imports & & & & & & & & \\
\hline Code2 & Imports & & & & & & & & \\
\hline Code3 & Imports & & & & & & & & \\
\hline II_fob & TOT & & & & & & & & \\
\hline TXSP & TOT & & & & & & & & \\
\hline others & TOT & & & & & & & & \\
\hline VA & TOT & & & & & & & & \\
\hline GO & TOT & go1 & go2 & go3 & & & & & \\
\hline
\end{tabular}

There are standard notations used in NIOT.

(A) Codes of industries.

EXP - txports;

(B) The notations concerning components of final

$\mathrm{GO}$ - total (gross) output at basic prices. demand:

(C) The notations of the table lower part rows:

II_fob - total intermediate consumption;

CONS_h - final consumption expenditure by

TXSP - taxes less subsidies on products; households;

$\mathrm{VA}$ - value added at basic prices.

CONS_np - final consumption expenditure by non- Others - means the aggregated following profit organisations serving households (NPISH);

CONS_g - final consumption expenditure by government;

GFCF - gross fixed capital formation;

INVEN - changes in inventories and valuables;

indicators:

EXP_adj - cif/fob adjustments on exports;

PURR - Direct purchases abroad by residents;

PURNR - purchases on the domestic territory by non-residents;

IntTTM - International Transport Margins.

Let us introduce notations and relations used in our study. Assume that the open economy is categorized into $\mathrm{n}$ sectors (industries). We consider the industry as the abstract economic subjectproducer, which in definite period of time buys the input vector and using of purchased input with help of owned current technologies produces and sells the output vector. Economic equilibrium means equality between the value of input and the value of output. Let $i, j=1,2, \ldots, n$.

1. The structure of the balancing equation (1) characterizes the input utilized for producing in the $j$-th industry one monetary unit of total output.

$$
d_{1 j}+d_{2 j}+\ldots+d_{n j}+m_{1 j}+m_{2 j}+\ldots+m_{n j}+v_{j}=1,
$$

where $d_{i j}$-domestic interindustry coefficient;

$m_{i j}$ - imported resources intermediate consumption coefficient'

$v_{j}$ - value added created by one monetary unit of total output in the $j$-th industry.

The vector-column

$$
\left(D_{j j}, M_{j j}, v_{j}\right):=\left(d_{1 j}, d_{2 j}, \ldots, d_{n j}, m_{1 j}, m_{2 j}, \ldots, m_{n j}, v_{j}\right)^{T} \in \mathbf{R}^{n+n+1,1}
$$


shows the average production costs for producing one monetary unit of output, and value added created withal. The vector $\left(D_{\cdot j}, M_{\cdot j}, v_{j}\right)$ indicates the purchasing structure of $j$-th industry in order to produce one monetary unit of gross output. This vector is determined by technological standards and specifications of $j$-th industry and domestic economy capacity.

2. The concept of value added in microeconomics, macroeconomics and in the WIOD.

In microeconomics an acceptable definition of firm's created value added is given in the book [17] Economics by Äke Blomqvist, Paul Wonnacott, Ronald Wonnacott "Value added. Value of the product sold less the cost of intermediate products bought from other firms".

The macroeconomic concept of value added created by an industry is explained in the European Central Bank Glossary [18]: "Value added (gross) is total output less the intermediate consumption". Eurostat definition $[19 ; 20]$ : $G D P=$ compensation of employees + gross operating surplus + net taxes on production and imports. In our opinion, the input-output approach is a better way to study the basic economic indicators of national economy in its interaction for an understanding of how the system works. The Input-Output model is necessary to understand the logic of the definitions given by the European Central Bank and Eurostat. Let us critically remark that WIOD does not explore the complete structure of value added ("compensation of employees + gross operating surplus + net taxes on production and imports") and it makes impossible to investigate the distribution of created wealth between different economic agents.

3. The structure of the balancing equation (2) characterizes the utilization of the monetary unit of the $j$-th industry gross output as domestic allocation coefficients and final demand.

$$
g_{j 1}+g_{j 2}+\ldots+g_{j n}+w_{j}=1,
$$

where $g_{j k}$ is the domestic allocation coefficient - the part of $j$-th industry monetary unit sold to the $k$-th industry, $w_{j}$ is the part of $j$-th industry monetary unit sold to the final consumers.

The most important parts of the final demand $\mathrm{w}_{\mathrm{j}}$ are the CONS_h (Final consumption expenditure by households), CONS_g (Final consumption expenditure by government), EXP (Exports), GFCF (Gross fixed capital formation), CONS_np (Final consumption expenditure by non-profit organisations serving households). Let us interpret the vector-row

$$
\left(G_{j}, w_{j}\right):=\left(g_{j 1}, g_{j 2}, \ldots, g_{j n}, w_{j}\right) \in \mathbf{R}^{1, n+1}
$$

as the sales revenue vector of one monetary gross output unit made from the $j$-th industry.

4. From the industry's point of view we mostly do not make the difference - are the resources bought domestically or imported, we are interested only in intermediate average costs of the product.

As value added (gross) is total output less the intermediate consumption, for the firm it does not make sense - are the purchases made from domestic firms or from foreign firms. (Of course, if additional transaction costs do not arise during import.) Let us call the vector $A_{{ }_{j}}:=D_{\cdot j}+M_{{ }_{j}}$ as technology of $j$-th industry. The matrix

$$
A:=\left(A_{1} A_{2} \ldots A \cdot n\right) \in \mathbf{R}^{n, n}
$$

is called the technology matrix of the given national economy.

In sense of the national macroeconomics as a whole there is a sufficient difference between domestic purchases D and foreign purchases $M$. Let us shortly remind the I-O basic equalities in the matrix form. From direct model $X=D X+Y$ and dual model $P-D^{T} P-M^{T} P=V$ follows

$$
P \cdot Y=P \cdot X-P \cdot D X=P \cdot X-D^{T} P \cdot X ; P \cdot X-D^{T} P \cdot X-M^{T} P \cdot X=V \cdot X ; P \cdot Y=M^{T} P \cdot X+V \cdot X,
$$

where $X-$ vector of gross output;

$Y$ - vector of the final demand;

$P$ - vector of the price indices;

$V$ - vector of gross value added.

In the formulas the matrix multiplication and scalar product of vectors is applied. Therefore, the value of the final demand $P \cdot Y$ equals the gross value added $V \cdot X$ plus imports' intermediate expenditures 
$M^{T} P \cdot X$. For that reason, the gross value added of the separate industry usually is smaller than the value of the final demand of the industry.

5. Net exports are the value of a nation's total export goods and services minus the value of all the goods and services it imports. A nation's net exports characterize the balance of trade: a positive net export indicates a trade surplus, while a negative net export means a trade deficit.

Considering the role of separate $j$-th industry in the national balance of trade forming, we compare (a) the value of $j$-th industry imports for intermediate consumption and (b) the value of $j$-th industry exports.

a) The expenditures for the foreign purchases utilized for producing in the $j$-th industry one monetary unit of total output is

$$
m_{1 j}+m_{2 j}+\ldots+m_{n j}
$$

where $m_{i j}$-imported $i$-th resources intermediate consumption coefficient.

The sum direct

$$
m_{1 j}+m_{2 j}+\ldots+m_{n j}
$$

is known as the backward linkage of $j$-th industry with respect to the import and denoted as " $D B L_{j} \_$import".

b) The revenue received from export forms a part of $j$-th industry monetary unit sold to the final consumers; let us denote as $E X P_{j}$.

In our opinion, the trade balance of the industry " $E X P_{j}-D B L_{j \_} i m p o r t$ " is an important and pithy interpreted economic indicator determined by a broad spectrum of the environmental PESTILB factors. Thus, we classified the industries as the trade surplus industries and as the trade deficit industries.

The total backward linkage of $j$-th industry to the import "TBL $L_{-}$import" (see note 3 and note 6 ) can be considered as the marginal trade balance indicator, which reflects the required balanced growth of imports to ensure increased export of the $j$-th industry by one monetary unit ,when all other industries' final products remain unchanged. So, we classified the industries as the trade marginal surplus industries and as the trade marginal deficit industries.

Note 1. Each industry as the subject-producer holds the equilibrium balance - for each monetary unit produced the sum of purchasing expenditures equals the sum of sales revenues:

$$
a_{1 j}+a_{2 j}+\ldots+a_{n j}+v_{j}=g_{j 1}+g_{j 2}+\ldots+g_{j n}+w_{j}=1 .
$$

In the market economy it is easy to buy and difficult to sell. Managers are more concerned about chances to get revenue $g_{j 1}+g_{j 2}+\ldots+g_{j n}+w_{j}$ than about the perspectives of purchases $a_{1 j}+a_{2 j}+\ldots+a_{n j}$. Better sales conditions ensure a bigger sum $g_{j 1}+g_{j 2}+\ldots+g_{j n}+w_{j}$, but the better purchasing conditions and more efficient production technology ensure a smaller sum $a_{1 j}+a_{2 j}+\ldots+a_{n j}$. As a result, the industry receives a bigger value added $v_{j}$ with respect to the monetary unit of output.

Note 2 . The sum $d_{1 j}+d_{2 j}+\ldots+d_{n j}$ is called the direct backward linkage of $j$-th industry with respect to the domestic economy (DBL_domestic); the sum $m_{1 j}+m_{2 j}+\ldots+m_{n j}$ is called the direct backward linkage of $j$-th industry with respect to the import (DBL_import); the sum $a_{1 j}+a_{2 j}+\ldots+a_{n j}$ is called the direct backward linkage of $j$-th industry $(D B L)$; the sum $g_{j 1}+g_{j 2}+\ldots+g_{j n}$ is called the direct forward linkage of $j$-th industry $(D F L)$.

Note 3. The vector-column

$$
\Lambda_{\mathrm{j}}:=\left(\lambda_{1 j}, \lambda_{2 j}, \ldots, \lambda_{n j}\right)^{T} \in \mathbf{R}^{n, 1},
$$

where $\lambda_{i j}$ - element of the Leontief inverse matrix $\Lambda:=(I-D)^{-1}$,

reflects the required balanced growth of all $\mathrm{n}$ domestic industries outputs to ensure increased final product of the $j$-th industry by one monetary unit, when all other industries' final products remain unchanged.

The vector-column

$$
(M \Lambda)_{j}:=\left(\mu_{1 j}, \mu_{2 j}, \ldots, \mu_{n j}\right)^{T} \in \mathbf{R}^{n, 1},
$$

where $\mu_{i j}$-element of transformed import matrix $M \Lambda$, 
reflects the required growth of all $n$ imported products to ensure the balanced increasing of the final $j$-th product by one monetary unit, when all other industries' final products remain unchanged.

Note 4. The vector-row

$$
\Gamma_{j}:=\left(\gamma_{j 1}, \gamma_{j 2}, \ldots, \gamma_{j n}\right) \in \mathbf{R}^{1, \mathrm{n}},
$$

where $\gamma_{i j}$-element of the Ghosh inverse matrix $\Gamma:=(I-G)^{-1}$,

reflects the required balanced growth of all $\mathrm{n}$ domestic industries outputs to ensure the balanced $j$-th industry's value added increasing by one monetary unit, when all other industries' added values remain unchanged.

Note 5. The vectors-columns $\Lambda_{\mathrm{j}},(M \Lambda)_{\mathrm{j}}$ are useful for economic analysis, because they describe the necessary increase in the domestic output and import to provide balanced increasing of the $j$-th final product by one monetary unit, when all other industries' final demands remain unchanged. Such information allows us to estimate the likelihood of a $j$-th final product increase. For instance, if the impact on the domestic output or on the import from such action is unrealistically big, then the action is not real. If the impact is relatively small, then we have to study the sales problem: how to ensure the balance

$$
a_{1 j}+a_{2 j}+\ldots+a_{n j}+v_{j}=g_{j 1}+g_{j 2}+\ldots+g_{j n}+w_{j}=1 .
$$

Analogically, the vector row $\Gamma_{\mathrm{j}}$. allows us to estimate in the marginal sense required growth of all $\mathrm{n}$ domestic industries gross outputs to ensure the balanced $j$-th industry's value added increasing by one monetary unit, when all other industries' added values remain unchanged.

Note 6. The sum $\lambda_{1 j}+\lambda_{2 j}+\ldots+\lambda_{n j}$ is called the total backward linkage of $j$-th industry to the domestic economy $(T B L)$; the sum $\mu_{1 j}+\mu_{2 j}+\ldots+\mu_{n j}$ is called the total backward linkage of $j$-th industry to the import (TBL_import); the sum $\gamma_{j 1}+\gamma_{j 2}+\ldots+\gamma_{j n}$ is called the total forward linkage of $j$-th industry to the domestic economy (TFL).

Note 7. The Input-Output model is fundamentally linear in nature. We consider the input-output balancing linear equation systems as the comparative statics models, which allow us to introduce a number of the pithy interpreted significant economic marginal indicators useful for the endogenous and exogenous economical and technological perturbances analysis: interindustry coefficients, elements of Leontief inverse matrix, allocation coefficients and elements of Ghosh inverse matrix. Models allow to estimate the intersectoral dependencies and marginal linkages of the industry $\mathrm{C} 10-\mathrm{C} 12$ in the national economy and structure of required imports. All economical and technological interpretations of indicators are based on the mathematical connections resulting from the Input-Output model. The main mathematical tool for the Input-Output model holistic analysis is the pivot transformation (often called as Jordan-Gauss elimination). Pivot transformation is algorithmized equivalent transformation of the system of linear equations and simultaneous equivalent transformation of corresponding dual system of linear equations. Both are interpreted as predicates. Idea of pivot transformation as simultaneous equivalent transformation of two predicates is absolutely simple, but incredibly fruitful in linear algebra. Let us shortly consider the mathematics of the pivot transformation.

Let $\mathbf{E}, \mathbf{F}$ vector spaces. Let $a, b, c, d \in \mathbf{R} ; a \neq 0 ; X_{1}, X_{2}, Y_{1}, Y_{2} \in \mathbf{E} ; U_{1}, U_{2}, V_{1}, V_{2} \in \mathbf{F}$. Direct system of equations

$$
\left\{Y_{1}=a X_{1}+b X_{2} ; Y_{2}=c X_{1}+d X_{2}\right\}
$$

can be transformed as system

$$
\left\{X_{1}=a^{-1} Y_{1}-b a^{-1} X_{2} ; Y_{2}=c a^{-1} Y_{1}+(a d-b c) a^{-1} X_{2}\right\} .
$$

Dual system of equations

$$
\left\{U_{1}=a V_{1}+c V_{2} ; U_{2}=b V_{1}+d V_{2}\right\}
$$

can be transformed as system

$$
\left\{-V_{1}=a^{-1}\left(-U_{1}\right)+c a^{-1} V_{2} ; U_{2}=b a^{-1}\left(-U_{1}\right)+(a d-b c) a^{-1} V_{2}\right\} .
$$

We offer to consider these four systems of equations as predicates. Condition $a \neq 0$ is sufficient and necessary for equivalency of direct system and its transformed system with respect to variables $a, b, c$, 
$d \in \mathbf{R} ; X_{1}, X_{2}, Y_{1}, Y_{2} \in \mathbf{E}$, and for equivalency of dual system and its transformed system with respect to variables $a, b, c, d \in \mathbf{R} ; U_{1}, U_{2}, V_{1}, V_{2} \in \mathbf{F}$ as well.

Remark. We demonstrated just $(2 \times 2)$-matrix in order to be simple. Of course, the number of vectors $X_{i} \in \mathbf{E}$ and number of vectors $Y_{j} \in \mathbf{F}$ are arbitrary.

Note 8. Our conclusions about the industry C10-C12 different efficiency in EST, FIN, LVA, LTU obtained with help of indicators calculated have a descriptive character. For the exculpation let us assert that it is typically for scientific papers nowadays. However, the Economics has to be a causal science with the rigorous detailed socio-economic causality analysis taking into account real human capital and human behaviour. In order to explain the deepest reasons of the week development during so long time period economists must return to the holistic style of investigation demonstrated by Ronald Coase, Friedrich Hayek, James Buchanen and others.

\section{Results and discussion}

In order to get a complete holistic view on the industry's "Manufacture of food products, beverages and tobacco products" (C10-C12) economics in EST, FIN, LVA, LTU an array of indicators according to the chapter "Materials and Methods" is calculated. The interpretations of indicators are based on the mathematical relationships resulting from the pivot transformations of the Input-Output model as a system of linear equations. Let us stress that the interpretations of indicators often have the marginal sense holding proper ceteris paribus condition. The industries in the International Standard Industrial Classification are strictly defined and internationally recognized. It is handy to use the NIOT code of industries in the text. The codes and descriptions used in NIOT are provided in the paper [14], Table 7. We recommend employing the NIOT codes on a regular basis for more unified and precise scientific understanding of the meaning of each industry.

1. The scale of the industry $\mathrm{C} 10-\mathrm{C} 12$ operating in the referred countries.

Let us observe that in the Baltic States the industry C10-C12 (Manufacture of food products, beverages and tobacco products) is one of the ten biggest (see Table 1). In Latvia in 2014 industry's C10-C12 gross output equals $4.02 \%$ of the national economy total gross output 64725.66 . In Finland industry's $\mathrm{C} 10-\mathrm{C} 12$ gross output equals $2.90 \%$ of the national economy total gross output 513657.88 .

Latvia's C10-C12 gross output volume 2602.37, for example, comparing with Lithuania's 5759.52 shows that Latvia has potential to increase the $\mathrm{C} 10-\mathrm{C} 12$ gross output.

Table 1

Ten biggest Latvian industries measured by the current industry's gross output (in millions of US dollars) 2014

\begin{tabular}{|c|c|c|c|c|c|c|c|c|c|c|}
\hline Code & F & L68 & H52 & G46 & D35 & H49 & O84 & C16 & C10-C12 & G47 \\
\hline EST & 4119.45 & 3217.55 & 3065.45 & 2658.30 & 1949.89 & 2479.09 & 2354.77 & 2310.04 & 2286.94 & 2034.02 \\
\hline FIN & 38102.71 & 42882.65 & 8959.40 & 19785.35 & 11414.47 & 12758.91 & 26822.42 & 7650.83 & 14885.84 & 15564.71 \\
\hline LVA & $\mathbf{7 3 5 6 . 7 3}$ & $\mathbf{4 9 5 0 . 5 1}$ & $\mathbf{4 1 7 4 . 1 4}$ & $\mathbf{4 1 5 4 . 0 7}$ & $\mathbf{3 7 2 9 . 1 1}$ & $\mathbf{3 4 6 0 . 6 0}$ & $\mathbf{2 9 9 5 . 7 4}$ & $\mathbf{2 6 8 6 . 9 9}$ & $\mathbf{2 6 0 2 . 3 7}$ & $\mathbf{2 5 1 3 . 8 6}$ \\
\hline LTU & 5970.31 & 3886.87 & 3327.49 & 5550.91 & 2661.48 & 5983.60 & 3698.92 & 1387.32 & 5759.52 & 4306.86 \\
\hline
\end{tabular}

Code and description:

$\mathrm{F}$ - construction

L68 - real estate activities

H52 - warehousing and support activities for transportation

G46 - wholesale trade, except of motor vehicles and motorcycles

D35 - electricity, gas, steam and air conditioning motorcycles.

supply

2. Excerpts from the NIOT 2014, which cover industry's C10-C12 (Manufacture of food products, beverages and tobacco products) expenditures and revenues in current prices, expressed in millions of US dollars.

Tables 2 and 3 contain the general indicators that describe C10-C12 intermediate consumption. 
Industry's "Manufacture of food products, beverages and tobacco products" expenditures

Table 2 (in millions of US dollars) in EST, FIN, LVA, LTU

\begin{tabular}{|c|l|l|l|l|c|}
\hline Code & Description & \multicolumn{1}{|c|}{ EST } & \multicolumn{1}{|c|}{ FIN } & \multicolumn{1}{c|}{ LVA } & LTU \\
\hline- & Intermediate consumption (domestic) & 1175.99 & 9608.68 & 1135.91 & 2337.40 \\
\hline- & Intermediate consumption (imports) & 521.41 & 2084.68 & 617.31 & 1319.99 \\
\hline II_fob & Total intermediate consumption & 1697.40 & 11693.36 & 1753.22 & 3657.39 \\
\hline GVA & Gross value added at basic prices & 589.53 & 3192.49 & 849.15 & 2102.13 \\
\hline VA & Net value added at basic prices & 493.86 & 3423.54 & 687.32 & 2003.29 \\
\hline GO & Output at basic prices & 2286.94 & 14885.84 & 2602.37 & 5759.52 \\
\hline
\end{tabular}

Table 3

Industry's "Manufacture of food products, beverages and tobacco products" expenditures in EST, FIN, LVA, LTU with respect to monetary unit of output

\begin{tabular}{|c|l|c|c|c|c|}
\hline Code & Description & EST & FIN & LVA & LTU \\
\hline- & Intermediate consumption (domestic) & 0.5142 & 0.6455 & 0.4365 & 0.4058 \\
\hline- & Intermediate consumption (imports) & 0.2280 & 0.1400 & 0.2372 & 0.2292 \\
\hline II_fob & Total intermediate consumption & 0.7422 & 0.7855 & 0.6737 & 0.6350 \\
\hline GVA & Gross value added at basic prices & 0.2578 & 0.2145 & 0.3263 & 0.3650 \\
\hline VA & Net value added at basic prices & 0.2159 & 0.2300 & 0.2641 & 0.3478 \\
\hline GO & Output at basic prices & 1 & 1 & 1 & 1 \\
\hline
\end{tabular}

Note. In Finland the net value added is bigger than the gross value added because of indicator "taxes less subsidies on products" is negative, -358.78 . Tables 4 and 5 contain the general indicators of C10C12 describing the gross output sales allocation.

Table 4

Industry's C10-C12 intermediate sales and final demand in EST, FIN, LVA, LTU

\begin{tabular}{|c|c|c|c|c|c|c|c|c|}
\hline Code & Intermediate sales & CONS_h & CONS_np & CONS_g & GFCF & INVEN & EXP & GO \\
\hline EST & 477.62 & 765.26 & 0.63 & 1.86 & 5.27 & 50.19 & 986.11 & 2286.94 \\
\hline FIN & 7754.17 & 4539.69 & 0.55 & 32.10 & 88.67 & 85.20 & 2385.46 & 14885.84 \\
\hline LVA & 367.76 & 1103.95 & 0.04 & 1.88 & 5.51 & -134.98 & 1258.22 & 2602.37 \\
\hline LTU & 309.26 & 3167.57 & 0.12 & 0.45 & 11.11 & -420.21 & 2691.22 & 5759.52 \\
\hline
\end{tabular}

Code and description:

CONS_h - final consumption expenditure by households

INVEN - changes in inventories and valuables

CONS_g -final consumption expenditure by government

GFCF - gross fixed capital formation

EXP - Exports

$\mathrm{GO}$ - ndustry's gross output.

CONS_np - final consumption expenditure by non-profit organisations serving households

(NPISH)

The comparative approach gives us the matter for investigation.

Table 2 and Table 3 give us the worthy of attention signal about Finland's C10-C12 expenditures in contrast with C10-C12 in EST, LVA, LTU. Namely, in Finland the imported intermediate consumption equals only $18 \%$ from the total industry's intermediate consumption, when the corresponding indicators of EST, LVA, LTU are $31 \%, 35 \%, 36 \%$. That fact is worth to investigate more rigorously. What is the reason? We will try to find the roots of that, so say, self-sufficiency of Finland's industry $\mathrm{C} 10-\mathrm{C} 12$ analysing the structure of the input vector.

Table 4 gives us analogical worthy of attention insight about the industry's C10-C12 sales vector structure. The role of industry $\mathrm{C} 10-\mathrm{C} 12$ in the national economy of the referred countries is different. The intermediate domestic sales in FIN make 52\% of gross output but in EST, LVA, LTU accordingly only $21 \%, 14 \%, 5 \%$. We are sure that Finland's industry C10-C12 significant domestic intermediate purchases (65\% of GO) and significant domestic intermediate sales (52\% of GO) enriched the Finland's economy as a whole. At the same time, we also have to investigate unusually small percent of the C10C12 intermediate sales in Lithuania: only $5 \%$ of GO. 
Industry's C10-C12 final demand in EST, FIN, LVA, LTU

with respect to monetary unit of output

\begin{tabular}{|c|c|c|c|c|c|c|c|c|}
\hline Code & Intermediate sales & CONS_h & CONS_np & CONS_g & GFCF & INVEN & EXP & GO \\
\hline EST & 0.2088 & 0.3346 & 0.0003 & 0.0008 & 0.0023 & 0.0219 & 0.4312 & 1 \\
\hline FIN & 0.5209 & 0.3050 & 0.0000 & 0.0022 & 0.0060 & 0.0057 & 0.1603 & 1 \\
\hline LVA & 0.1413 & 0.4242 & 0.0000 & 0.0007 & 0.0021 & -0.0519 & 0.4835 & 1 \\
\hline LTU & 0.0537 & 0.5500 & 0.0000 & 0.0001 & 0.0019 & -0.0730 & 0.4673 & 1 \\
\hline
\end{tabular}

In our opinion, the economists assess as positive indication the fact that Finland's total intermediate sales equal $52 \%$ of gross output and proper final demand is $48 \%$ from the gross output. At the same time, intermediate sales only $5 \%$ of gross output in Lithuania signalize about week influence of industry $\mathrm{C} 10-\mathrm{C} 12$ to the economic activities of the rest LTU industries.

3. Excerpts from the NIOT 2014, which cover industry's C10-C12 (Manufacture of food products, beverages and tobacco products) revenues from exports and expenditures for imports in current prices, expressed in millions of US dollars.

Figure 1 depicts dynamics of industry's C10-C12 export. It reveals notable differences in the export of $\mathrm{C} 10-\mathrm{C} 12$ product in FIN and other countries of reference.

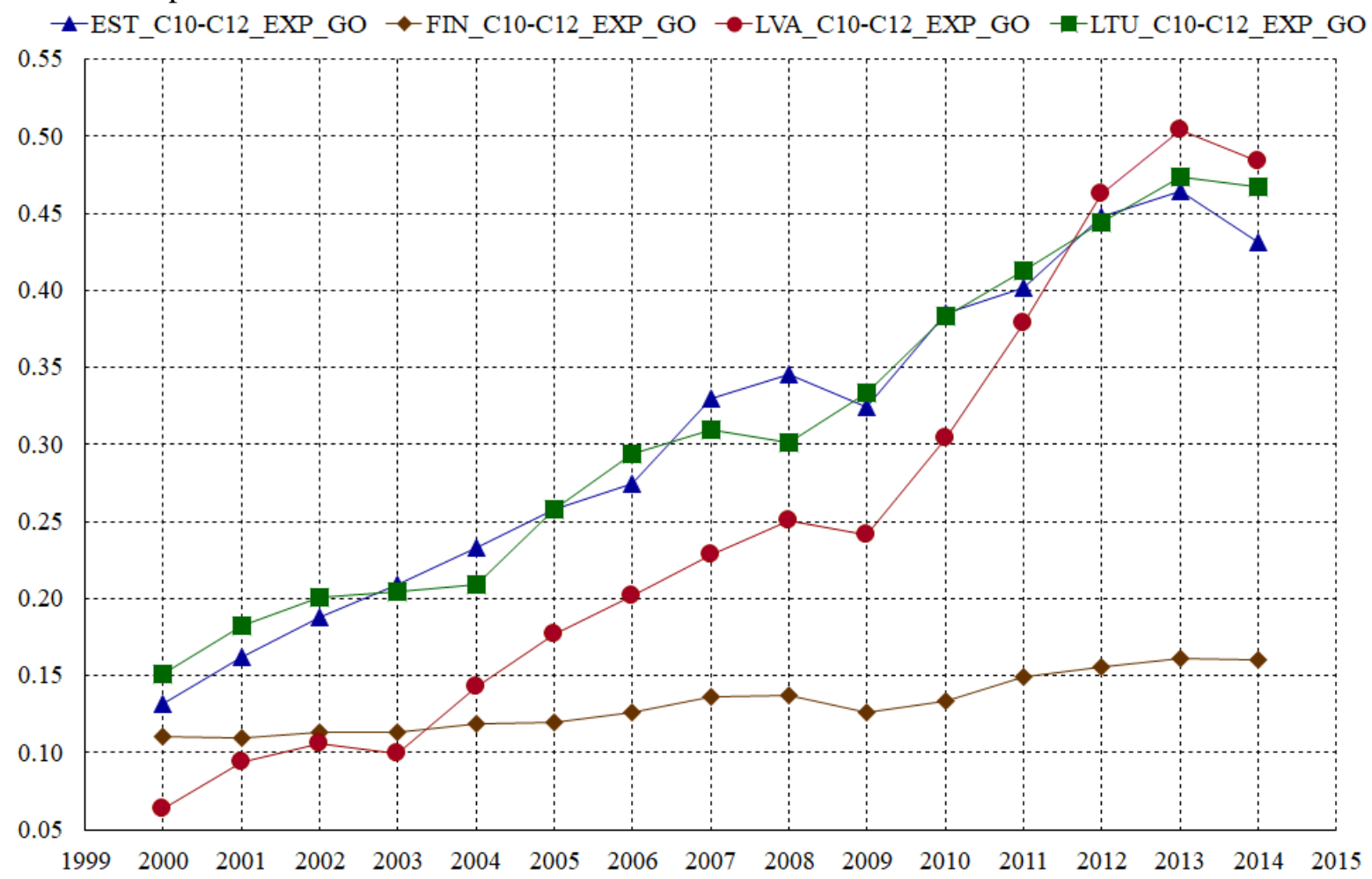

Fig. 1. Dynamics of the industry's C10-C12 exports as share of C10-C12 gross output in EST, FIN, LVA, LTU in 2000-2014

Since 2004 export of Finland's C10-C12 is less than C10-C12 export in EST, LVA. LTU. Noteworthy is the growing difference between exports of FIN and other referred countries. In 2014 industry's $\mathrm{C} 10-\mathrm{C} 12$ export is $16 \%$ from the industry's $\mathrm{C} 10-\mathrm{C} 12$ gross output what is sufficiently less compared to $43 \%$ (EST), $48 \%$ (LVA), 47\% (LTU). Although in the absolute numbers FIN takes the second place with 2385 against 2681 for LTU (in 2014), it becomes clear that Finland does not qualify as a significant industry "Manufacture of food products, beverages and tobacco products" exporter. At the same time, percent of export in EST, LVA, LTU is similar.

What is the industry C10-C12 trade balance in the referred countries? Data displayed in Table 2 and in Table 3 show: the industries C10-C12 in EST, FIN, LVA, LTU are trade balance positive. Table 6 shows the trade balance of some other industries. 
Trade balance of the industry C10-C12 in EST, FIN, LVA, LTU with respect Table 6 to one unit of industry's gross output, 2014, (ten industries arranged by trade balance, from largest to smallest)

\begin{tabular}{|l|c|c|c|c|c|c|c|c|c|c|c|}
\hline \multicolumn{1}{|c|}{ Trade balance } & C19 & C21 & H50 & C20 & C29 & C28 & C26 & C27 & C31-C32 & C16 & C10-C12 \\
\hline EST (import) & 0.1923 & 0.4492 & 0.3241 & 0.6108 & 0.5214 & 0.4531 & 0.7648 & 0.5294 & 0.3461 & 0.1979 & 0.2280 \\
\hline EST (export) & 0.3996 & 0.7089 & 0.6190 & 0.9469 & 0.9748 & 0.9455 & 0.9890 & 0.9537 & 0.8394 & 0.7443 & 0.4312 \\
\hline EST (trade balance) & 0.2074 & 0.2597 & 0.2949 & 0.3361 & 0.4534 & 0.4924 & 0.2242 & 0.4242 & 0.4933 & 0.5464 & 0.2032 \\
\hline FIN (import) & 0.5959 & 0.0989 & 0.2128 & 0.2777 & 0.3982 & 0.3079 & 0.2648 & 0.2949 & 0.2141 & 0.0900 & 0.1400 \\
\hline FIN (export) & 0.6508 & 0.4924 & 0.5488 & 0.4478 & 0.8967 & 0.6731 & 0.4684 & 0.8365 & 0.5295 & 0.4548 & 0.1603 \\
\hline FIN (trade balance) & 0.0549 & 0.3935 & 0.3360 & 0.1701 & 0.4985 & 0.3652 & 0.2037 & 0.5416 & 0.3154 & 0.3649 & 0.0202 \\
\hline LVA (import) & 0.1299 & 0.1074 & 0.0515 & 0.2971 & 0.3358 & 0.3498 & 0.3605 & 0.3814 & 0.2439 & 0.1376 & 0.2372 \\
\hline LVA (export) & 1.0000 & 0.9468 & 0.7656 & 0.9592 & 0.9731 & 0.9683 & 0.9783 & 0.9908 & 0.7993 & 0.5985 & 0.4835 \\
\hline LVA (trade balance) & $\mathbf{0 . 8 7 0 1}$ & $\mathbf{0 . 8 3 9 4}$ & $\mathbf{0 . 7 1 4 1}$ & $\mathbf{0 . 6 6 2 0}$ & $\mathbf{0 . 6 3 7 3}$ & $\mathbf{0 . 6 1 8 5}$ & $\mathbf{0 . 6 1 7 8}$ & $\mathbf{0 . 6 0 9 5}$ & $\mathbf{0 . 5 5 5 4}$ & $\mathbf{0 . 4 6 1 0}$ & $\mathbf{0 . 2 4 6 3}$ \\
\hline LTU (import) & 0.7275 & 0.0570 & 0.1524 & 0.5335 & 0.2336 & 0.2909 & 0.2714 & 0.3945 & 0.2089 & 0.2982 & 0.2292 \\
\hline LTU (export) & 0.7042 & 0.8449 & 0.4968 & 0.8386 & 0.9722 & 0.9237 & 0.9661 & 0.9736 & 0.8391 & 0.6100 & 0.4673 \\
\hline LTU (trade balance) & -0.0233 & 0.7880 & 0.3444 & 0.3051 & 0.7386 & 0.6328 & 0.6947 & 0.5792 & 0.6302 & 0.3118 & 0.2381 \\
\hline
\end{tabular}

All industries in Table 6 are trade balance positive and thereby strengthen the trade balance of the national economy. Of course, also industries with negative trade balance exist. For instance, in LVA the trade balance for industry C18 is $0.1657-0.3615=-0.1958$; for D35 is $0.0396-0.1942=-0.1546$; for $\mathrm{I}$ is $0.0111-0.1194=-0.1084$. In Finland the industry D35 has the trade balance 0.0371$0.1862=-0.1481$; the industry $\mathrm{F}$ has $0.0010-0.1366=-0.1357$.

4. Dynamics of the industry's C10-C12 value added as part of gross output in EST, FIN, LVA, LTU (2000-2014).

Figure 2 depicts the time series of industry's C10-C12 net value added as part of gross output in EST, FIN, LVA, LTU for period 2000-2014.

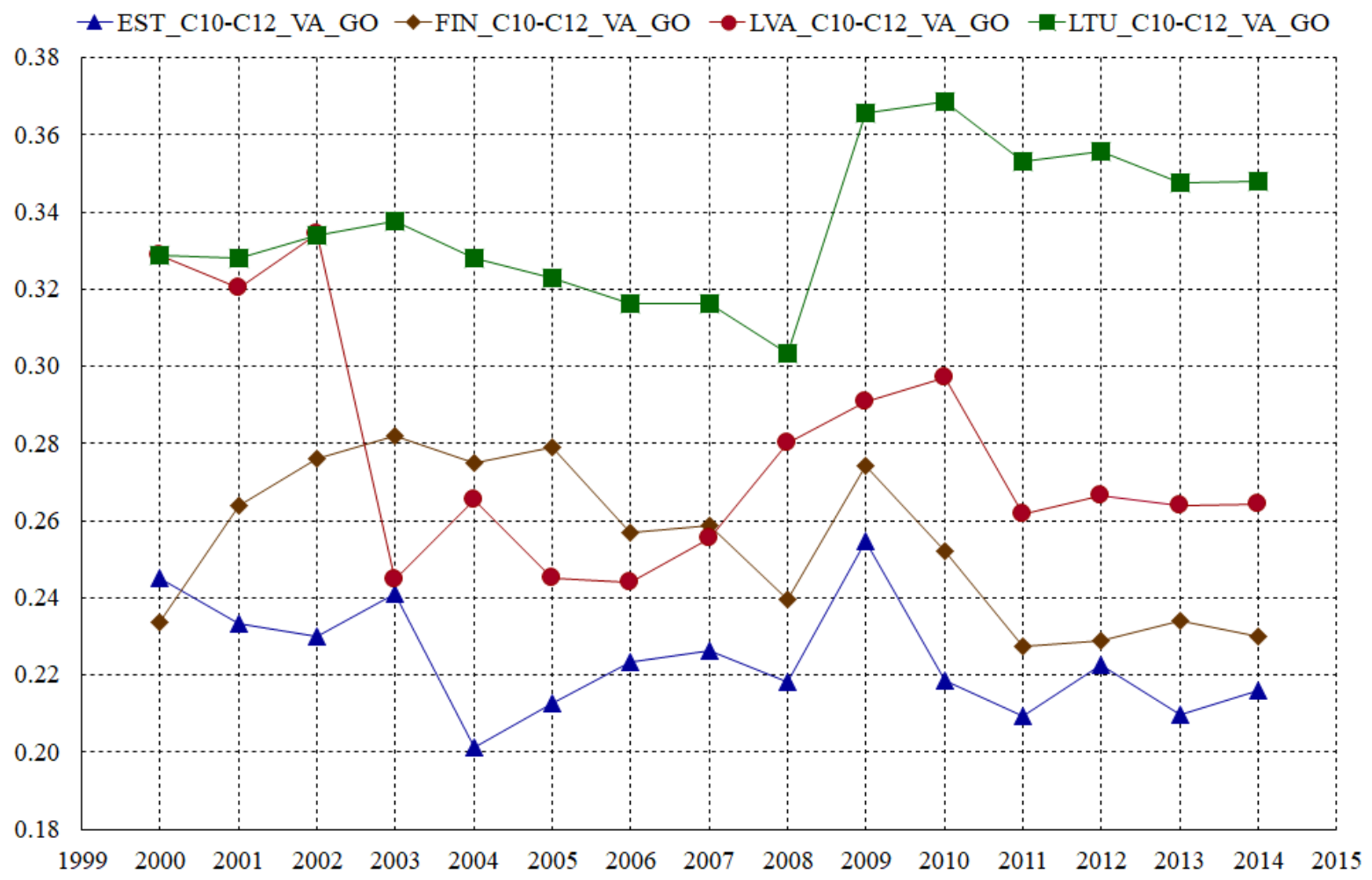

Fig. 2. Dynamics of C10-C12 net value added as part of industry's gross output in EST, FIN, LVA, LTU in 2000-2014 
Our attention is focused on the Latvian graph with its dramatically decreasing in 2002-2003. One of the reasons is the Latvian mandatory procurement public service obligation fee, so called "OIK fraud", what sufficiently increases costs of electricity in Latvian economy.

Let us observe that in the last four years there is stabilization of the net value added in each of the referred countries.

5. Comparison and analysis of intermediate consumption.

Table 7 contains two arranged (from largest to smallest) excerpts from the total C10-C12 intermediate consumption matrix (2014): arrangement by LVA indicators and arrangement by FIN indicators. We observe sufficient distinction in the line of largest total intermediate consumptions (domestic plus imported purchases) per monetary unit of total output. In order to explain the difference, further examination is needed.

Table 7

Industry's C10-C12 ten biggest input (domestic plus imported) indicators in LVA and FIN

(2014) (components of the vectors $A_{j}:=D_{j}+M_{j}$ ).

\begin{tabular}{|c|c|c|c|c|c|c|c|c|c|}
\hline Code & EST & FIN & LVA & LTU & Code & EST & FIN & LVA & LTU \\
\hline C10-C12 & 0.163 & 0.213 & 0.169 & 0.065 & A01 & 0.205 & 0.234 & 0.141 & 0.219 \\
\hline $\mathrm{A} 01$ & 0.205 & 0.234 & 0.141 & 0.219 & $\mathrm{C} 10-\mathrm{C} 12$ & 0.163 & 0.213 & 0.169 & 0.065 \\
\hline G47 & 0.010 & 0.003 & 0.039 & 0.026 & G46 & 0.064 & 0.035 & 0.037 & 0.033 \\
\hline G46 & 0.064 & 0.035 & 0.037 & 0.033 & $\mathrm{H} 49$ & 0.046 & 0.035 & 0.028 & 0.022 \\
\hline D35 & 0.021 & 0.019 & 0.034 & 0.016 & H52 & 0.012 & 0.029 & 0.021 & 0.027 \\
\hline H49 & 0.046 & 0.035 & 0.028 & 0.022 & $\mathrm{C} 22$ & 0.023 & 0.020 & 0.020 & 0.039 \\
\hline $\mathrm{C} 17$ & 0.013 & 0.020 & 0.023 & 0.016 & $\mathrm{C} 17$ & 0.013 & 0.020 & 0.023 & 0.016 \\
\hline $\mathrm{H} 52$ & 0.012 & 0.029 & 0.021 & 0.027 & D35 & 0.021 & 0.019 & 0.034 & 0.016 \\
\hline $\mathrm{C} 22$ & 0.023 & 0.020 & 0.020 & 0.039 & $\mathrm{C} 20$ & 0.020 & 0.018 & 0.005 & 0.003 \\
\hline M69_M70 & 0.015 & 0.015 & 0.017 & 0.010 & M69_M70 & 0.015 & 0.015 & 0.017 & 0.010 \\
\hline DBL_domestic & 0.5142 & 0.6455 & 0.4365 & 0.4058 & & & & & \\
\hline DBL_imports & 0.2280 & 0.1400 & 0.2372 & 0.2292 & & & & & \\
\hline DBL_total & 0.7422 & 0.7855 & 0.6737 & 0.6350 & & & & & \\
\hline
\end{tabular}

We recognize that the Latvian $\mathrm{C} 10-\mathrm{C} 12$ (Manufacture of food products, beverages and tobacco products) has notably bigger compared with the referred countries intermediate consumption for the products of the industries G47 (Retail trade, except of motor vehicles and motorcycles) and D35 (Electricity, gas, steam and air conditioning supply). Especially big difference is between proper coefficients in LVA and FIN. Dramatically high expenses for electricity in Latvia are widely discussed. The retail trade costs in Latvia are more than 10 times higher than in FIN, but are still analysed not sufficiently.

Figure 3 shows notably differences in the technologies of the industries C10-C12 in EST, FIN, LVA, LTU. What does 0.065 LTU signalize versus 0.213 FIN about? The industry C10-C12 in FIN utilize products of $\mathrm{C} 10-\mathrm{C} 12$ approximately 3.5 times more intensive than LTU. If there is not the peculiarity in LTU statistics methodology, the managers of C10-C12 in LTU have to analyse such distinction.

Figure 4 shows how the product of industry A01 (Crop and animal production, hunting and related service activities) as intermediate consumption is utilized in the industry C10-C12.

Latvian C1-C12 has its own specific. For example, in 2014 opposite to Finland's 0.234 is Latvian 0.141 .

Figures 5, 6, 7 depict some time series of intermediate consumption per monetary unit of gross output.

Figure 5 asks the question to the Estonian economists about the twice more coefficient concerning the industry's C10-C12 intermediate consumption of G46 (Wholesale trade, except of motor vehicles and motorcycles) product compared with EST, FIN, LVA. 


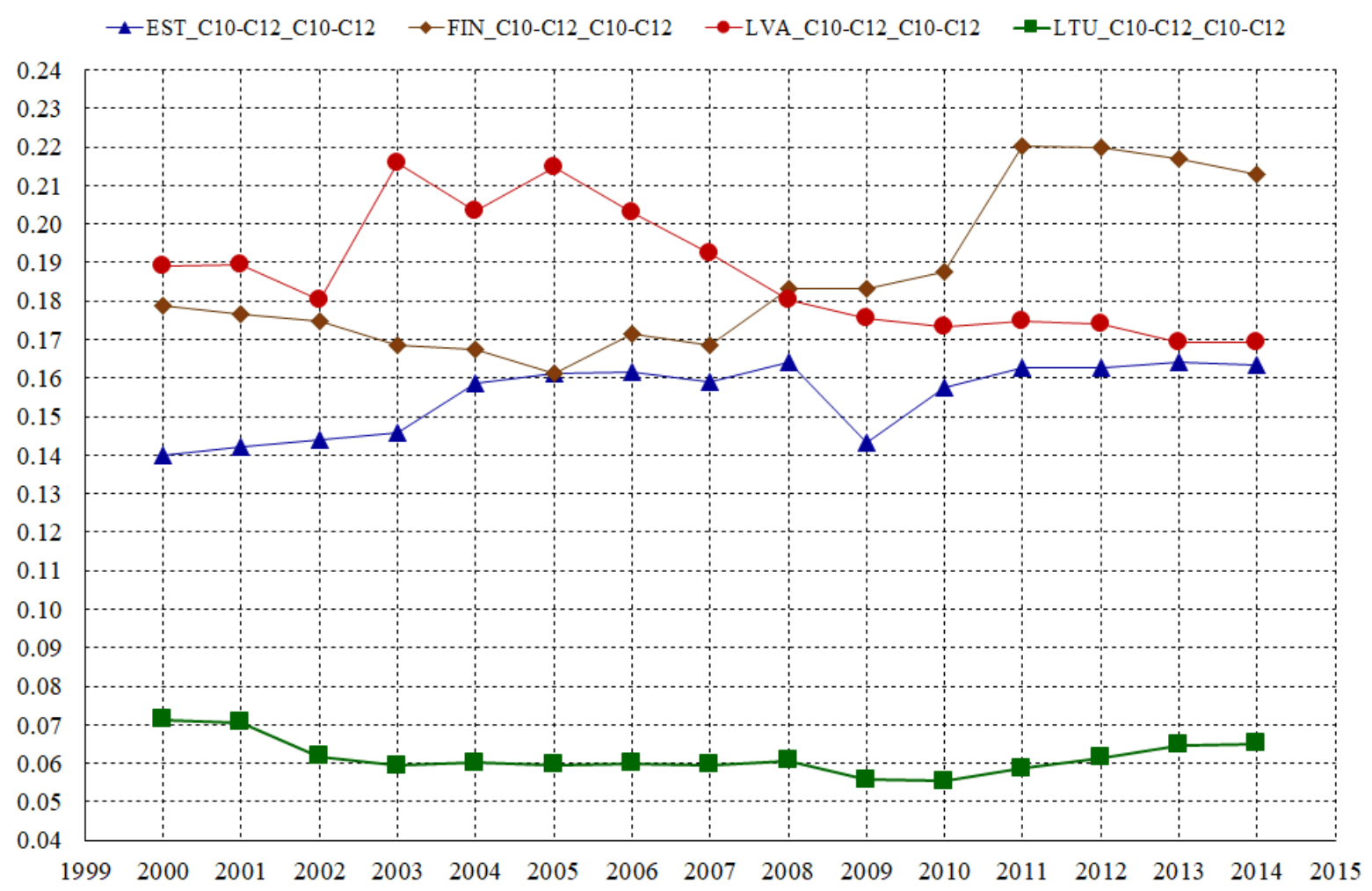

Fig. 3. Dynamics of C10-C12 product intermediate consumption as part of C10-C12 one monetary unit gross output

Figure 6 demonstrates notable differences in the intermediate expenses of C10-C12 relating to D35 (Electricity, gas, steam and air conditioning supply). In 2014 in LVA the intermediate product cost of D35 is 0.034 with respect to one monetary unit of gross output. At the same time, in EST this indicator is 0.021 , in FIN it equals to 0.019, in LTU it equals 0.016.

$₫-$ EST_C10-C12_A01 $\rightarrow$-FIN_C10-C12_A01 $\rightarrow$ LVA_C10-C12_A01 $\rightarrow$-LTU_C10-C12_A01

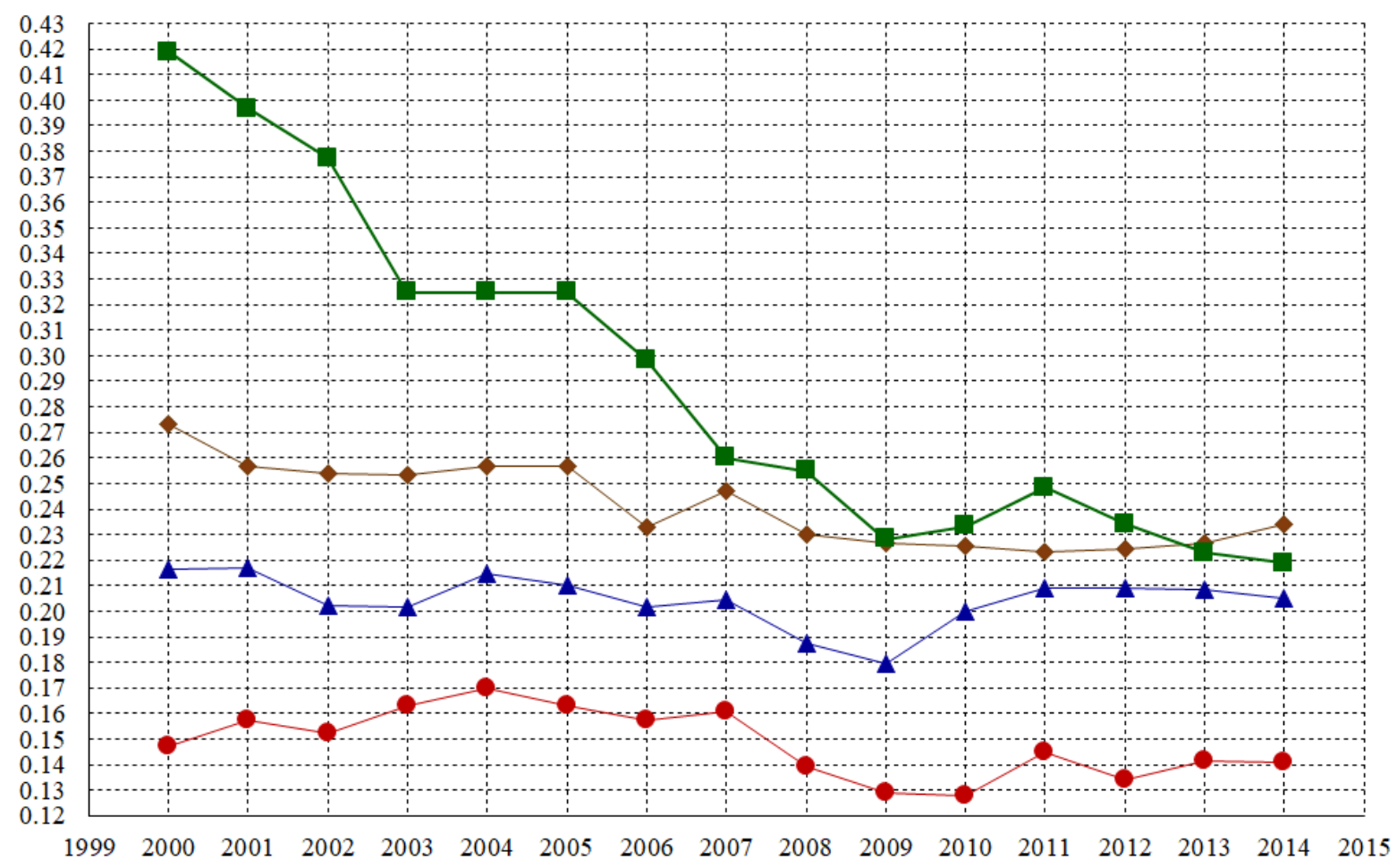

Fig. 4. Dynamics of industry's A01 (Crop and animal production, hunting and related service activities) product intermediate consumption as part of C10-C12 one monetary unit gross output 


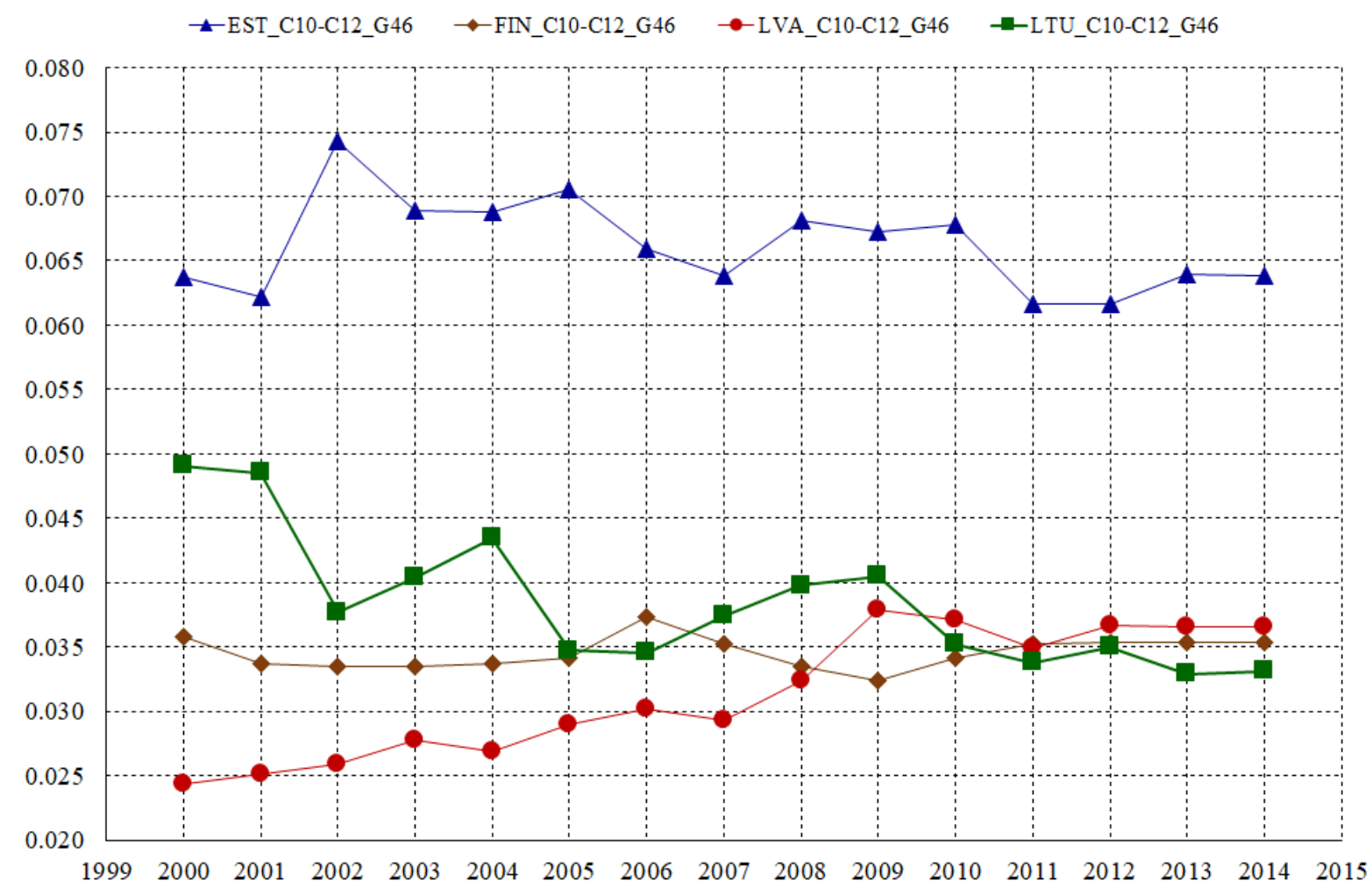

Fig. 5. Dynamics of industry's G46 (Wholesale trade, except of motor vehicles and motorcycles ) product intermediate consumption as part of C10-C12 one monetary unit gross output

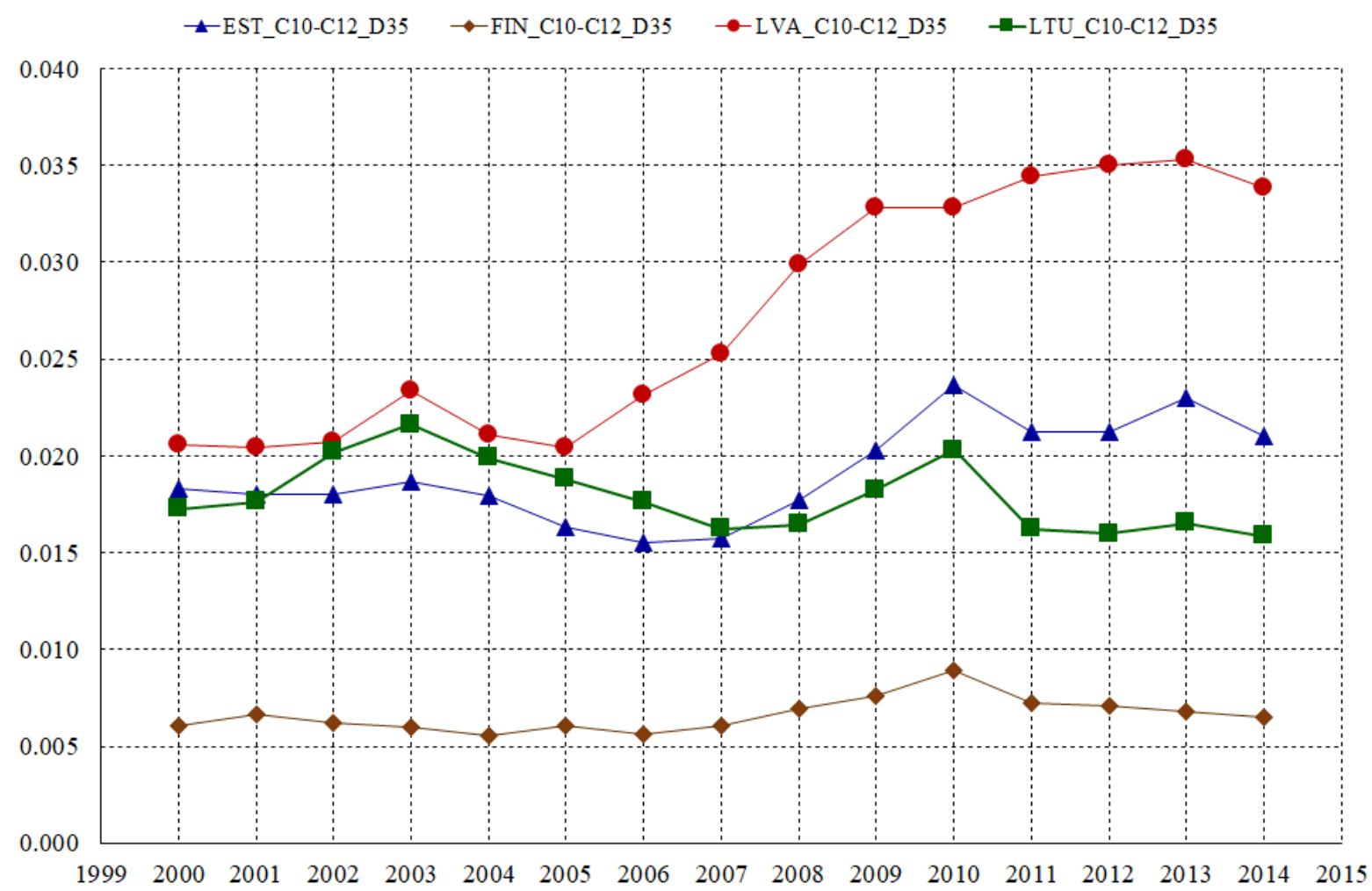

Fig. 6. Dynamics of industry's D35 (Electricity, gas, steam and air conditioning supply) product intermediate consumption as part of C10-C12 one monetary unit gross output

It is not surprising that purchases of electricity in LVA are many times larger than in other countries of reference. Indeed, the Latvian mandatory procurement public service obligation fee (in Latvian obligātà iepirkuma komponente $(O I K))$ undermines competitiveness of the Latvian economy. This is a 
bad sign for Latvian competitive power. After the parliamentary (Saeima) elections of 2018 the new political forces called OIK a fraud.

Figure 7 demonstrates the notable stable difference between intermediate consumption coefficients of the industry's G47 (Retail trade, except of motor vehicles and motorcycles) product as resource of the industry C10-C12 (Manufacture of food products, beverages and tobacco products). As it was mentioned before, the Latvian C10-C12 intermediate consumption coefficient of the industry's G47 product is notably bigger compared with the referred countries. In our opinion, the time series depicted in Figure 7 comprise the serious economic problem what is still analysed not sufficiently. This requires further examination together with industry $\mathrm{C} 10-\mathrm{C} 12$ and $\mathrm{G} 47$ experts. But now, we can only recommend to $\mathrm{C} 10-\mathrm{C} 12$ managers to visit their Finnish colleagues and to learn their management success.

The direct backward linkages (Table 7) summarize the results of intermediate average costs investigation. The average costs with respect to one monetary unit of gross output in industry C10-C12 in the referred countries are approximately equal. It signalizes about similar technological conditions in the $\mathrm{C} 10-\mathrm{C} 12$ production process. At the same time, sufficient differences are in the structure of equation "DBL_total = DBL_domestic + DBL_imports", what signalize that different PESTILB factors influenced the industry $\mathrm{C} 10-\mathrm{C} 12$ in these countries.

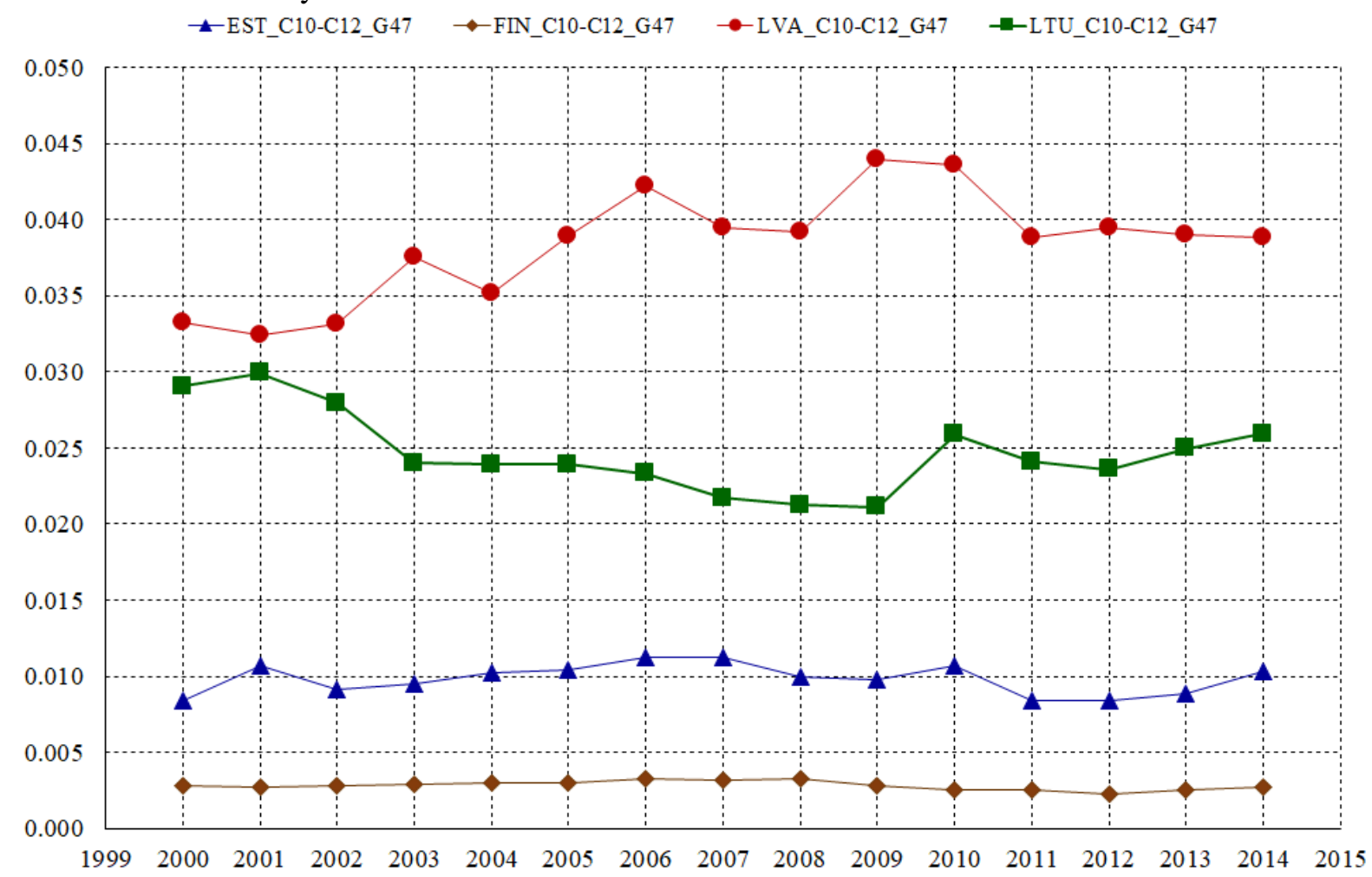

Fig. 7. Dynamics of industry's G47 (Retail trade, except of motor vehicles and motorcycles) product intermediate consumption as part of C10-C12 one monetary unit gross output

6. Comparison and analysis of allocation coefficients.

Table 8 contains two arranged (from largest to smallest) excerpts from the allocation matrices G: arrangement by LVA indicators and arrangement by FIN indicators. Table 8 reveals notable differences in intermediate sales structure of $\mathrm{C} 10-\mathrm{C} 12$ product in LVA and other countries of reference. Observe that in the both parts of Table 8 the numbers concerning FIN are bigger than the numbers for LVA.

One of reasons that is easily observable is the difference in relatively small purchases of C10-C12 product by industry I (Accommodation and food service activities). Industry I bought with respect to one monetary unit of C10-C12 gross output (see table 8): in EST 0.0453; in FIN 0.0971; in LVA 0.0295; in LTU 0.0046. Let us note that in our previous studies we have observed that the industry I (Accommodation and food service activities) in FIN is an active buyer of domestic industry's A01 (Crop and animal production, hunting and related service activities) products. Obviously, in Finland the industry "Accommodation and food service activities" is much more developed comparing with Latvia 
and Lithuania. In order to explain the difference, further examination of industry's "Accommodation and food service activities" economics is necessary.

As it was expected, the product of industry C10-C12 sold to the households is important part of industry's total sales. In Latvia $42 \%$ of the industry's C10-C12 gross output is bought by households (CONS_h); in Estonia 33\%, in Finland 31\%, in Lithuania 55\%. Sufficient differences among the intermediate buyers of industry's C10-C12 product show the direct forward linkage (DFL). For LTU this indicator equals DFL (LTU, C10-C12, 2014) $=0.0537$, for LVA DFL (LVA, C10-C12, $2014)=0.1413$, what is small comparing with DFL $($ EST, C10-C12, 2014 $)=0.2088$ and especially with DFL $($ FIN, C10-C12, 2014) $=0.5209$.

In our opinion, in order to elaborate upgraded management decisions, it is worth to investigate the deepest reasons of the differences between the sales structure and, generally, the differences between direct forward linkages. Further investigation is needed together with the industry $\mathrm{C} 10-\mathrm{C} 12$ experts taking in account the real PESTILB environment in the proper countries. There is a lot of information to investigate. For example, let us consider the sales relating to industry Q (Human health and social work activities): Latvian 0.0025 against to Finnish 0.0138. It appears to us that it is not difficult to explain these differences and to take in account the Finnish experience.

Industry's C10-C12 ten biggest allocations coefficients for LVA and FIN (2014)

Table 8 (components of the vectors $G_{j}$.)

\begin{tabular}{|c|c|c|c|c|c|c|c|c|c|c|}
\hline Code & $\begin{array}{c}\text { C10- } \\
\text { C12 }\end{array}$ & I & P85 & Q & G46 & $\begin{array}{c}\text { R_S + } \\
\text { T+U }\end{array}$ & F & H49 & H52 & D35 \\
\hline EST & 0.1007 & 0.0453 & 0.0055 & 0.0024 & 0.0024 & 0.0014 & 0.0008 & 0.0007 & 0.0013 & 0.0011 \\
\hline FIN & 0.1923 & 0.0971 & 0.0061 & 0.0138 & 0.0046 & 0.0098 & 0.0106 & 0.0014 & 0.0081 & 0.0039 \\
\hline LVA & $\mathbf{0 . 0 8 6 9}$ & $\mathbf{0 . 0 2 9 5}$ & $\mathbf{0 . 0 0 3 8}$ & $\mathbf{0 . 0 0 2 5}$ & $\mathbf{0 . 0 0 2 1}$ & $\mathbf{0 . 0 0 1 8}$ & $\mathbf{0 . 0 0 1 5}$ & $\mathbf{0 . 0 0 1 5}$ & $\mathbf{0 . 0 0 1 3}$ & $\mathbf{0 . 0 0 0 9}$ \\
\hline LTU & 0.0212 & 0.0046 & 0.0002 & 0.0018 & 0.0020 & 0.0005 & 0.0005 & 0.0004 & 0.0002 & 0.0001 \\
\hline
\end{tabular}

\begin{tabular}{|c|c|c|c|c|c|c|c|c|c|c|}
\hline Code & $\begin{array}{c}\text { C10- } \\
\text { C12 }\end{array}$ & I & A01 & C20 & Q & N & O84 & J62_J63 & F & C17 \\
\hline EST & 0.1007 & 0.0453 & 0.0213 & 0.0041 & 0.0024 & 0.0017 & 0.0017 & 0.0002 & 0.0008 & 0.0003 \\
\hline FIN & $\mathbf{0 . 1 9 2 3}$ & $\mathbf{0 . 0 9 7 1}$ & $\mathbf{0 . 0 4 8 6}$ & $\mathbf{0 . 0 2 4 1}$ & $\mathbf{0 . 0 1 3 8}$ & $\mathbf{0 . 0 1 3 2}$ & $\mathbf{0 . 0 1 2 3}$ & $\mathbf{0 . 0 1 0 7}$ & $\mathbf{0 . 0 1 0 6}$ & $\mathbf{0 . 0 1 0 1}$ \\
\hline LVA & 0.0869 & 0.0295 & 0.0007 & 0.0007 & 0.0025 & 0.0007 & 0.0008 & 0.0003 & 0.0015 & 0.0000 \\
\hline LTU & 0.0212 & 0.0046 & 0.0126 & 0.0004 & 0.0018 & 0.0001 & 0.0004 & 0.0001 & 0.0005 & 0.0000 \\
\hline
\end{tabular}

Code and description:

D35 - electricity, gas, steam and air conditioning

I - accommodation and food service activities

P85 - education

$\mathrm{Q}$ - human health and social work activities

G46 - wholesale trade, except of motor

vehicles and motorcycles

$\mathrm{R} \_\mathrm{S}+\mathrm{T}+\mathrm{U}-$ ther service activities

$\mathrm{F}-$ construction

H49 - land transport and transport via

pipelines

H52 - warehousing and support activities for transportation

supply

A01 - crop and animal production, hunting and

related service activities

C20 - manufacture of chemicals and chemical

products

$\mathrm{N}$ - administrative and support service activities

O84 - public administration and defence;

compulsory social security

J62_J63 - computer programming, consultancy and

related activities; information service activities

C17 - manufacture of paper and paper products.

7. Comparison and analysis of the impact of the $\mathrm{C} 10-\mathrm{C} 12$ final demand increase on the total output required for equilibrium in the national economy.

Table 9 contains two arranged (from largest to smallest) excerpts from the Leontief inverse $\Lambda$ : arrangement by LVA indicators and arrangement by FIN indicators. We can observe notable distinction in the national industries' necessary reaction to the $\mathrm{C} 10-\mathrm{C} 12$ final demand increase in order to provide economic equilibrium in the national economy. For example, as it was expected, in LVA the big pressure is related to the pitifully famous Latvian industry D35 (Electricity, gas, steam and air conditioning supply): 0.0751 in LVA against 0.0238 in LTU. 
Let us remind that the Leontief coefficients are marginal indicators of comparative statics. For example, the coefficient 0.0751 means the following: required balanced growth of D35 gross output in case, if the final demand of $\mathrm{C} 10-\mathrm{C} 12$ increases by one monetary unit, when the final demand of all the other industries remains unchanged is 0.0751 . Leontief coefficients have important economical sense revealed in the $\mathrm{C} 10-\mathrm{C} 12$ final demand increasing impact to the domestic industry A01 (Crop and animal production, hunting and related service activities) gross output. For FIN that indicator equals 0.2663 , for LVA it is only 0.1443. In the opinion of the authors, the role of Latvian A01 gross output in the formation of the industry's C10-C12 final demand will increase.

Tables 10 and 11 show the LVA and FIN industries with ten biggest and with ten smallest backward linkages (TBL_domestic). According to economic essence of Leontief's inverse the domestic backward linkage (TBL_domestic) indicates the impact on the rest national industries caused by an increase in the final demand in C10-C12 by one monetary unit, when the final demand of all the other industries remains unchanged. The indicator TBL_imports indicates the impact on the whole national imports caused by an increase in the final demand in C10-C12 by one monetary unit, when the final demand of all the other industries remains unchanged.

Table 9

Industry's C10-C12 twelve biggest Leontief coefficients for LVA and FIN (2014) (components of the vectors $\Lambda_{j}$ )

\begin{tabular}{|c|c|c|c|c|}
\hline Code & EST & FIN & LVA & LTU \\
\hline C10-C12 & 1.1228 & 1.2821 & $\mathbf{1 . 0 9 6 2}$ & 1.0261 \\
\hline A01 & 0.2143 & 0.2663 & $\mathbf{0 . 1 4 4 3}$ & 0.1874 \\
\hline D35 & 0.0359 & 0.0387 & $\mathbf{0 . 0 7 5 1}$ & 0.0238 \\
\hline H52 & 0.0339 & 0.0618 & $\mathbf{0 . 0 6 5 1}$ & 0.0334 \\
\hline G46 & 0.0724 & 0.0627 & $\mathbf{0 . 0 5 3 4}$ & 0.0409 \\
\hline G47 & 0.0298 & 0.0069 & $\mathbf{0 . 0 4 7 1}$ & 0.0289 \\
\hline H49 & 0.0662 & 0.0607 & $\mathbf{0 . 0 4 3 2}$ & 0.0320 \\
\hline L68 & 0.0251 & 0.0292 & $\mathbf{0 . 0 2 3 1}$ & 0.0153 \\
\hline M69_M70 & 0.0184 & 0.0191 & $\mathbf{0 . 0 2 3 0}$ & 0.0156 \\
\hline N & 0.0207 & 0.0342 & $\mathbf{0 . 0 2 0 9}$ & 0.0177 \\
\hline F & 0.0090 & 0.0267 & $\mathbf{0 . 0 2 0 6}$ & 0.0118 \\
\hline K64 & 0.0128 & 0.0146 & $\mathbf{0 . 0 1 3 3}$ & 0.0104 \\
\hline TBL_domestic & 1.8265 & 2.2358 & $\mathbf{1 . 7 6 3 4}$ & 1.5775 \\
\hline TBL_imports & 0.3821 & 0.3144 & $\mathbf{0 . 3 7 4 0}$ & 0.3367 \\
\hline & & & &
\end{tabular}

\begin{tabular}{|c|c|c|c|c|}
\hline Code & EST & FIN & LVA & LTU \\
\hline $\begin{array}{c}\text { C10- } \\
\text { C12 }\end{array}$ & 1.1228 & $\mathbf{1 . 2 8 2 1}$ & 1.0962 & 1.0261 \\
\hline A01 & 0.2143 & $\mathbf{0 . 2 6 6 3}$ & 0.1443 & 0.1874 \\
\hline G46 & 0.0724 & $\mathbf{0 . 0 6 2 7}$ & 0.0534 & 0.0409 \\
\hline H52 & 0.0339 & $\mathbf{0 . 0 6 1 8}$ & 0.0651 & 0.0334 \\
\hline H49 & 0.0662 & $\mathbf{0 . 0 6 0 7}$ & 0.0432 & 0.0320 \\
\hline D35 & 0.0359 & $\mathbf{0 . 0 3 8 7}$ & 0.0751 & 0.0238 \\
\hline N & 0.0207 & $\mathbf{0 . 0 3 4 2}$ & 0.0209 & 0.0177 \\
\hline C20 & 0.0027 & $\mathbf{0 . 0 2 9 6}$ & 0.0014 & 0.0046 \\
\hline L68 & 0.0251 & $\mathbf{0 . 0 2 9 2}$ & 0.0231 & 0.0153 \\
\hline C17 & 0.0007 & $\mathbf{0 . 0 2 7 4}$ & 0.0052 & 0.0004 \\
\hline F & 0.0090 & $\mathbf{0 . 0 2 6 7}$ & 0.0206 & 0.0118 \\
\hline O84 & 0.0020 & $\mathbf{0 . 0 2 2 7}$ & 0.0019 & 0.0005 \\
\hline
\end{tabular}

LVA industries with ten biggest and with ten smallest TBL_domestic

\begin{tabular}{|c|c|c|c|c|c|c|c|c|c|c|}
\hline Code & H52 & C19 & C16 & D35 & F & H51 & M73 & A02 & K65 & H49 \\
\hline TBL_domestic & 2.2395 & 2.2022 & 2.1677 & 2.0962 & 2.0953 & 2.0543 & 2.0234 & 1.9843 & 1.9606 & 1.8642 \\
\hline TBL_import & 0.2195 & 0.2840 & 0.2864 & 0.3818 & 0.3148 & 0.3968 & 0.2267 & 0.2485 & 0.1432 & 0.3064 \\
\hline
\end{tabular}

\begin{tabular}{|c|c|c|c|c|c|c|c|c|c|c|}
\hline Code & M72 & Q & P85 & C26 & C25 & C27 & C22 & C17 & C28 & C29 \\
\hline TBL_domestic & 1.1499 & 1.2957 & 1.3149 & 1.3344 & 1.3351 & 1.3762 & 1.3765 & 1.3890 & 1.4202 & 1.4372 \\
\hline TBL_import & 0.0612 & 0.2018 & 0.0984 & 0.3946 & 0.4749 & 0.4290 & 0.5228 & 0.5078 & 0.4095 & 0.4216 \\
\hline
\end{tabular}

FIN industries with ten biggest and with ten smallest TBL_domestic

\begin{tabular}{|c|c|c|c|c|c|c|c|c|c|c|}
\hline Code & $\begin{array}{c}\text { C10- } \\
\text { C12 }\end{array}$ & C16 & C17 & H52 & H51 & A01 & I & C24 & C18 & F \\
\hline TBL_domestic & 2.2358 & 2.1191 & 2.0941 & 2.0621 & 2.0458 & 1.9144 & 1.8941 & 1.8873 & 1.8468 & 1.8024 \\
\hline TBL_import & 0.3144 & 0.1972 & 0.2884 & 0.2125 & 0.3232 & 0.2982 & 0.1848 & 0.4859 & 0.2447 & 0.2496 \\
\hline
\end{tabular}


Table 11 (continued)

\begin{tabular}{|c|c|c|c|c|c|c|c|c|c|c|}
\hline Code & A03 & C21 & M72 & A02 & P85 & E36 & L68 & Q & C19 & $\begin{array}{c}\text { C13- } \\
\text { C15 }\end{array}$ \\
\hline TBL_domestic & 1.2480 & 1.3161 & 1.3243 & 1.3388 & 1.3519 & 1.4151 & 1.4306 & 1.4458 & 1.4568 & 1.4719 \\
\hline TBL_import & 0.2081 & 0.1428 & 0.0803 & 0.0721 & 0.0638 & 0.2020 & 0.0858 & 0.1030 & 0.7098 & 0.4484 \\
\hline
\end{tabular}

8. Elasticities of the total gross output with respect to the final demand of C10-C12 in the Baltic States and Finland in 2014.

In order to indicate the different effects of comparative statics with help of the Input-Output model relationships the line of elasticities can be calculated.

Let us consider, for instance, elasticity of GO (total) with respect to the industry's C10-C12 final demand: $\mathrm{FD}(\mathrm{C} 10-\mathrm{C} 12) \cdot \mathrm{TBL}$ domestic(C10-C12)/GO (total).

Table 12 contains the elasticities of total gross output with respect to the final demand of the industry C10-C12 in the Baltic States and Finland in 2014.

Table 12

Elasticities of total gross output with respect to the industry's C10-C12 final demand in the Baltic States and Finland (2014)

\begin{tabular}{|c|c|c|c|c|}
\hline Code & TBL_domestic & Final demand & Total gross output & $\begin{array}{c}\text { Elasticity of } \\
\text { total gross output }\end{array}$ \\
\hline EST & 1.8265 & 1809.32 & 54483.17 & 0.0607 \\
\hline FIN & 2.2358 & 7131.67 & 513657.88 & 0.0310 \\
\hline LVA & 1.7634 & 2234.61 & 64725.66 & 0.0609 \\
\hline LTU & 1.5775 & 5450.26 & 85667.79 & 0.1004 \\
\hline
\end{tabular}

As it was expected, we can observe notable differences in the calculated elasticities among the industry "Manufacture of food products, beverages and tobacco products" because of differences in the final demands and domestic total backward linkages. It indicates significant distinction in the national industries' necessary reaction to the $\mathrm{C} 10-\mathrm{C} 12$ final demand increase in order to provide economic equilibrium in the national economy.

9. Comparison and analysis of the impact of the industry's C10-C12 value added increase on the total output required for equilibrium in the national economy.

Table 13 contains two arranged (from largest to smallest) excerpts from the Ghosh inverse $\Gamma$ : arrangement by LVA indicators and arrangement by FIN indicators.

Table 13

Industry's "Manufacture of food products, beverages and tobacco products" ten biggest Gosh inverse coefficients for LVA and FIN (components of the vectors $\Gamma_{j}$.)

\begin{tabular}{|c|c|c|c|c|c|c|c|c|c|c|}
\hline Code & $\begin{array}{c}\text { C10- } \\
\text { C12 }\end{array}$ & I & F & P85 & G46 & H52 & N & H49 & Q & $\begin{array}{c}\text { R_S + } \\
\text { T+U U }\end{array}$ \\
\hline EST & 1.1228 & 0.0521 & 0.0032 & 0.0076 & 0.0043 & 0.0036 & 0.0038 & 0.0021 & 0.0035 & 0.0032 \\
\hline FIN & 1.2821 & 0.1305 & 0.0290 & 0.0157 & 0.0167 & 0.0192 & 0.0233 & 0.0064 & 0.0370 & 0.0207 \\
\hline LVA & $\mathbf{1 . 0 9 6 2}$ & $\mathbf{0 . 0 3 2 9}$ & $\mathbf{0 . 0 0 4 8}$ & $\mathbf{0 . 0 0 4 6}$ & $\mathbf{0 . 0 0 4 5}$ & $\mathbf{0 . 0 0 3 7}$ & $\mathbf{0 . 0 0 3 2}$ & $\mathbf{0 . 0 0 3 1}$ & $\mathbf{0 . 0 0 3 1}$ & $\mathbf{0 . 0 0 2 7}$ \\
\hline LTU & 1.0261 & 0.0048 & 0.0009 & 0.0003 & 0.0024 & 0.0003 & 0.0004 & 0.0008 & 0.0021 & 0.0007 \\
\hline
\end{tabular}

\begin{tabular}{|c|c|c|c|c|c|c|c|c|c|c|}
\hline Code & $\begin{array}{c}\text { C10- } \\
\text { C12 }\end{array}$ & I & A01 & $\mathbf{C 2 0}$ & $\mathbf{Q}$ & $\mathbf{F}$ & $\mathbf{0 8 4}$ & $\mathbf{C 1 7}$ & $\mathbf{N}$ & $\begin{array}{c}\text { R_S + } \\
\text { T+U }\end{array}$ \\
\hline EST & 1.1228 & 0.0521 & 0.0282 & 0.0048 & 0.0035 & 0.0032 & 0.0037 & 0.0005 & 0.0038 & 0.0032 \\
\hline FIN & $\mathbf{1 . 2 8 2 1}$ & $\mathbf{0 . 1 3 0 5}$ & $\mathbf{0 . 0 7 1 9}$ & $\mathbf{0 . 0 3 7 7}$ & $\mathbf{0 . 0 3 7 0}$ & $\mathbf{0 . 0 2 9 0}$ & $\mathbf{0 . 0 2 7 1}$ & $\mathbf{0 . 0 2 5 6}$ & $\mathbf{0 . 0 2 3 3}$ & $\mathbf{0 . 0 2 0 7}$ \\
\hline LVA & 1.0962 & 0.0329 & 0.0014 & 0.0009 & 0.0031 & 0.0048 & 0.0017 & 0.0001 & 0.0032 & 0.0027 \\
\hline LTU & 1.0261 & 0.0048 & 0.0137 & 0.0009 & 0.0021 & 0.0009 & 0.0007 & 0.0001 & 0.0004 & 0.0007 \\
\hline
\end{tabular}


Let us remind that the element of the Ghosh inverse matrix $\Gamma:=(I-G)^{-1}$ reflects the required balanced growth of all $\mathrm{n}$ domestic industries outputs to ensure the balanced $j$-th industry's value added increasing by one monetary unit, when all other industries' added values remain unchanged.

The content of Table 13 confirms, from another point of view, the conclusion made before - the industry C10-C12 in LVA and LTU has to be qualified as industry with small total forward linkage:

TFL $(L V A, C 10-C 12,2014)=1.1813$; TFL $(L T U, C 10-C 12,2014)=1.0652$ opposite to TFL(FIN, C10-C12, 2014) $=1.9334$.

That conclusion indicates an impact on the rest of national industries caused by the value added increase in $\mathrm{C} 10-\mathrm{C} 12$.

\section{Conclusions}

1. The comparative analysis of the industry's "Manufacture of food products, beverages and tobacco products" intermediate consumption structure demonstrates that Finland's industry C10-C12 is more oriented to the domestic purchases and less to the imports what sufficiently differs from EST, LVA, LTU. The Finland's imported intermediate consumption equals only $18 \%$ from the total intermediate consumption, when the corresponding indicators of EST, LVA, LTU are $31 \%, 35 \%$, $36 \%$. The comparison of direct backward linkages - domestic and imports, confirms that conclusion.

2. The industry's "Manufacture of food products, beverages and tobacco products" sales structure demonstrates that Finland's intermediate domestic sales make 52\% of gross output but in EST, LVA, LTU accordingly only $21 \%, 14 \%, 5 \%$. The economists assess as positive indication enriching of Finalnd's economy as a whole due to the fact that Finland's total intermediate sales equal 52\% of the gross output and proper final demand is $48 \%$ from the gross output. Lithuanian economists have to investigate unusually small percent of the C10-C12 intermediate sales in Lithuania: only $5 \%$ of GO.

3. Noteworthy is the growing difference between exports of FIN and other referred countries. In 2014 industry's $\mathrm{C} 10-\mathrm{C} 12$ export is $16 \%$ from the industry's C10-C12 gross output, which is sufficiently less compared to 43\% (EST), 48\% (LVA), 47\% (LTU). It signalizes that Finland does not qualify as significant industry "Manufacture of food products, beverages and tobacco products" exporter.

4. The authors realize the limitedness of the current research, the first, due to the limited work resources and, the second, due to the scarcity of information in sense of available limited time period. However, the authors desired to pay attention to the unlimited abundance of research feasibilities served by Input-Output Economics. For instance, the rigorous micro-economical and technical analysis of the Latvian "Manufacture of food products, beverages and tobacco products" intermediate domestic and imported purchases and the structure of the vector of sales in the domestic economy compared with Estonia, Finland and Lithuania would be useful. The authors suggest the sufficient increase in Input-Output investigations and hope that the Input-Output research centre by the Ministry of Economics of the Republic of Latvia will be established.

\section{References}

[1] Leontief W. Input-Output Economics. Second Edition. - Oxford University Press. 1986, 436 p.

[2] Ghosh A. Input-Output Approach to an Allocation System. - Economica, Vol. 25, No. 1, 1958, pp. 58-64.

[3] Bjerkholt O. Kurz H.D. (eds.), Special Issue: The History of Input-Output Analysis, Leontief's Path and Alternative Tracks, Economic Systems Research, 18(4): 2006.

[4] Miller R. E., Blair P. D. Input-Output analysis. Foundations and extensions. Second Edition. Cambridge University Press, 2013, 750 p.

[5] Rose A., Miernyk W. Input-output analysis: the first fifty years. Economic Systems Research, 1(2), 1989, pp. 229-272.

[6] Walras L. Éléments d'économie politique pure (1899, 4th ed.; 1926, éd. définitive).

[7] Walras :. Elements of Pure Economics, trans. William Jaffé. - Irwin, 1954.

[8] Oosterhaven J. Rethinking Input-Output Analysis: A Spatial Perspective. - University of Groningen, The Netherlands. Series: SpringerBriefs In Regional Science. Publisher: Springer Nature Switzerland AG. Year: 2019. 
[9] Mukhopadhyay K. (Ed.) Applications of the Input-Output Framework. - McGill University Montreal, QC, Canada. Publisher: Springer Nature Singapore Pte Ltd., 2018.

[10] Tan R. R., Aviso K. B., Promentilla M.A.B., Yu K. D. S., Santos J. R. Input-output models for sustainable industrial systems: Implementation using LINGO. - Springer, Singapore. 2018.

[11] Raa T.T. The use-make framework and the derivation of functional forms in production theory. Economic Systems Research, vol. 31, NO 1, 2019, pp. 132-141.

[12] Timmer M. P., Dietzenbacher E., Los B., Stehrer R., de Vries G. J. An Illustrated User Guide to the World Input-Output Database: the Case of Global Automotive Production. - Review of International Economics, vol. 23, 2015, 575 p.

[13] Jaunzems A. Methods of measuring industry total factor productivity within an input-output framework. 16th International Scientific Conference on Engineering for Rural Development, Proceedings, Volume 16, Jelgava, Latvia, 2017, pp. 383-392.

[14] Jaunzems, A., Balode, I. Comparison of Backward and Forward Linkages for Industries in the Baltic States and Finland. 17th International Scientific Conference Engineering for Rural Development, Jelgava, Latvia, 2018, pp. 1029-1039. DOI: 10.22616/ERDev2018.

[15] Jaunzems A. Comparative dynamic analysis of value added created by industry "forestry and logging" in the Baltic states and Finland. 17th International Scientific Conference on Engineering for Rural Development. Proceedings, Latvia, Jelgava, 2018, pp. 1019-1028.

[16] Jaunzems A., Balode I. Comparative dynamic analysis of value added created by industry "Crop and animal production, Hunting and related service activities" in the Baltic States and Finland. 18th International Scientific Conference Engineering for Rural Development, Jelgava, Latvia, 2019, pp. 1104-1117.

[17] Blomqvist Ä., Wonnacott P., Wonnacott R. Economics. Third Canadian Edition. - McGraw-Hill Ryerson Limited, 1990, 795 pp.

[18] Glossary entries "V" [online] [21.03.2021] Available at: http://www.ecb.europa.eu/home/glossary/html/glossv.en.html.

[19] Glossary:Intermediate consumption [online] [21.03.2021] Available at: https://ec.europa.eu/eurostat/statisticsexplained/index.php?title=Glossary:Intermediate_consumption.

[20] Glossary:Gross value added [online] [21.03.2021] Available at: https://ec.europa.eu/eurostat/statistics-explained/index.php?title=Glossary:Gross_value_added. 